\title{
Modification and Characterization of Polyacrylic Acid for Metal Ion Recovery
}

\author{
Magdy Y. Abdelaal ${ }^{1,2, *}$, Mohammad S.I. Makki ${ }^{1}$, Tariq R.A. Sobahi ${ }^{1}$ \\ ${ }^{1}$ Chemistry Department, Faculty of Science, King Abdulaziz University, PO Box 80203, Jeddah 21589, Saudi Arabia \\ ${ }^{2}$ Chemistry Department, Faculty of Science, Mansoura University, 35516, Mansoura, Egypt \\ magdyabdelaal@yahoo.com, abdelaal@mans.edu.eg
}

\begin{abstract}
Polyacrylic acid was converted into modified polymers with the targeted functional groups through the reaction with different organic compounds such as some aromatic amines and acids. The obtained modified polymeric products have been characterized through FT-IR spectroscopic and thermal analyses. Modified acrylic polymers were tested for their ability to be used for heavy metal ion recovery from their aqueous solutions. They also were tested as polymeric antioxidants for PVC as a standard polymer by using the discoloration extent of PVC as a function of thermal degradation of PVC due to the thermal treatment. The obtained results were discussed and justified.
\end{abstract}

Keywords Modification, Polyacrylic Acid, Metal Ion Recovery, Thermal Stability, Aromatic Amines

\section{Introduction}

Polyacrylic acid (PAA) belongs to the class of commercial polymers produced on a large scale and widely used in various industries, agriculture, and medicine[1]. PAA, its salts and PAA-based polymeric materials are used as emulsifiers and thickening agents for aqueous solutions and dispersions of both natural and synthetic latexes, smoothing agents for synthetic fibers, sorbents and ion exchangers, aqueous quenching media, flocculants, plastics, etc.[2-5]. Copolymers of acrylamide and divinylbenzene are used as ion exchange resins as well as copolymers of acrylic acids with acrylamide and polyvinyl alcohol are known for their activity toward metal ion uptake to be applied in the metal ion preconcentration or removal[6]. Polymers and copolymers of acrylic acid are known as efficient flocculants used, in particular, for increasing the strength of special paper grades[7].

Hydrophilic properties of PAA explain its wider use in agriculture for presuming treatment of seeds, etc. In recent years, there has been a growing interest in PAA as a basis for obtaining various physiologically active polymeric substances capable of separating from the carrier molecule at definite site of the living organism and producing a targeted physiological action[8].

Both PAA and the related compounds are more widely used as polymeric carriers for proteins, enzymes, drugs and other biologically active substances. In the latter case, PAA can be used for solving two mutually related problems of the

* Corresponding author:

magdyabdelaal@yahoo.com (Magdy Y. Abdelaal)

Published online at http://journal.sapub.org/ajps

Copyright (C) 2012 Scientific \& Academic Publishing. All Rights Reserved chemistry and technology of biopolymer for medical applications[9]. The two problems are creation of synthetic polymeric materials for short-time or prolonged contact with blood and other tissues in the living organism and development of the synthesis methods, establishing the mechanisms of physiological action of the macromolecules of pharmaceutical preparations[10].

Microwave initiated grafting of polyacrylic acid onto carboxymethylcellulose (CMC) to synthesize CMC-g-PAA which has showed higher flocculation efficiency than $\mathrm{CMC}$ itself reflecting the role of polyacrylic acid in such application. The high flocculation efficiency of polyacrylic acid grafted CMC makes it a good candidate as flocculants for river water clarification[11].

Synthesis of PAA and its properties have been extensively studied and repeatedly reviewed. It will be only mentioned briefly some points of importance. PAA is obtained by polymerization of acrylic acid (AA) in the presence of photo-initiators or under the action $\gamma$-radiation[12]. In the solid state, AA converts into polymer on exposure to UV radiation. Hydrogen peroxide, alkali metal or ammonium persulfates, and cumene hudrogen peroxide initiate the polymerization of AA in aqueous solution. Only non-ionized AA molecules enter into the polymerization reaction and the minimum reaction rate is observed.

Aqueous media are preferred for the polymerization of AA whose concentration should not exceed $25 \%$ due to the exothermic nature of the reaction which is otherwise difficult to control. Polymerization of AA in non-aqueous solvents is initiated by organic peroxides, AIBN and some redox and other systems.

The most active polymers on the basis of esters, anhydrides, amides, and related PAA derivatives composed 
of the $-\mathrm{CH}_{2}-\mathrm{CH}(\mathrm{C}(=\mathrm{O}) \mathrm{X})$ - units, where $\mathrm{X}$ is $\mathrm{OR}$, OCOR, $\mathrm{NH}_{2}, \mathrm{NR}_{2}$, etc., can be synthesized using three pathways. First is grafting of the reactive physiologically active monomers onto PAA matrix with the formation of valence bonds. An example is the synthesis of some sulfanilamide preparations, hormones, and some other biologically active compounds with reactive $\mathrm{OH}$ or $\mathrm{NH}_{2}$ groups[13]. The second one is the condensation of polyacrylyl chloride, polyacryla mide, polyalkylacrylate, or polyacrylic acid salt with physiologically active substance containing the correspondi ng functional groups. The last one is the homo-polymerizati on of physiologically active acrylic acid substituent of the formula $\mathrm{CH}_{2}=\mathrm{CH}(\mathrm{C}(=\mathrm{O}) \mathrm{Y})$ - where $\mathrm{Y}$ is a pharmacophore group bound through oxygen or nitrogen atom.

The first investigations in the synthesis of PAA derivatives containing reactive functional groups were reported by Kern and Schulz[12,14]. By interaction of polymethacrylate with hydrazine they obtained a polyacryloylhydrazide which was converted by Curtius reaction into polyacryloylazide. This was followed by condensation with various carbonyl compounds yielding polyacryloylhydrazones. A reaction of polymethylacrylate with hydroxylamine led to polyacryloylhydroxamic acid. Interaction of the latter acid with the salts of various metal ions led to a series of the corresponding metal containing derivatives. There are many trials to prepare modified polyacrylic acids through the synthesis of modified monomers followed by their polymerization[15]. Although modified polymers with higher purity would be obtained, the chemical modification of the monomers is not simple and need many precautions beside it is not suitable for the recycling of polyacrylic acid wastes. The current work is aiming to preparation of different polyacrylic acid derivativ es through simple methodologies followed by characterizati on and utilization of them as polymeric anti-oxidant and as a tool for recovery of heavy metals from their aqueous solutions.

\section{Experimental Part}

\subsection{Materials and Techniques}

All chemicals were obtained from Aldrich and used as received without further purification unless otherwise mentioned. PVC (M.Wt.=100.000) was also obtained from Aldrich.

FT-IR Spectroscopic analysis was carried out using a Perkin-Elmer 1430 spectrophotometer in the range of $4000-400 \mathrm{~cm}^{-1}$. UV spectra were recorded on a double beam spectrophotometer to measure the extent of discoloration of the degraded PVC samples as a function of degradation time. ICP/AES in the department was used to determine the concentration of the heavy metal ions under investigation. Differential thermal analysis (DTA) was carried out with a Shimadzu thermo-analyzer (D-50), Japan. Samples were heated at $10^{\circ} \mathrm{C} / \mathrm{min}$ in a stream of dry nitrogen using sintered alumina $\left(\alpha-\mathrm{Al}_{2} \mathrm{O}_{3}\right)$ as thermally inert reference material.

\subsection{Synthesis of Polyacrylic Acid}

A solution of 0.2 mole of dibenzoylperoxide in THF was added to 2 mole of acrylic acid solution in THF while stirring. The mixture was purged with nitrogen for $30 \mathrm{~min}$ at $70^{\circ} \mathrm{C}$ and was continued for $30 \mathrm{~min}$ further at the same conditions before cooling to the room temperature. Polyacrylic acid was precipitated by pouring into $400 \mathrm{ml}$ of anhydrous diethyl ether. The obtained product was filtered off and washed successively with diethyl ether and methanol then dried overnight under vacuum at $40{ }^{\circ} \mathrm{C}$.

\subsection{Synthesis of Polyacryly Chloride}

About 1.4 mole of thionyl chloride was added dropwisely to 1 mole of polyacrylic acid in a round bottomed flask. The reaction mixture was stirred for $1 \mathrm{~h}$ at $60^{\circ} \mathrm{C}$ and left to cool to the room temperature. The unreacted thionyl chloride was collected by filtration. The obtained product was washed with methylene chloride and dried overnight in vacuum at $40{ }^{\circ} \mathrm{C}$.

\subsection{Synthesis of Poly-2-acryloxybenzoic Acid}

A solution of 0.25 mole salicylic acid and 0.75 mole of triethylamine in $300 \mathrm{ml}$ acetonitrite was added dropwise to 0.3 mole of polyacrylyl chloride pre-soaked in $100 \mathrm{ml}$ acetonitrite for $6 \mathrm{~h}$. After complete addition, the reaction mixture was stirred further for $6 \mathrm{~h}$ at $25^{\circ} \mathrm{C}$. The reaction mixture was filtered off and washed with methanol, $1 \mathrm{M} \mathrm{HCl}$, distilled water to remove the formed triethylamine hydrochloride and finally with diethyl ether. The obtained polyacryloxybenzoic acid was dried overnight under vacuum at $40{ }^{\circ} \mathrm{C}$.

\subsection{Synthesis of Poly-N-acroylaniline}

A cold solution of 0.07 mole of aniline in 100 methylene chloride was added portion-wise with stirring to 0.03 mole of polyacrylyl chloride soaked in $50 \mathrm{ml}$ methylene chloride. After the complete addition stirring was continued for 30 min further and the product was filtered off. The excess of aniline was removed by washing the precipitate with methylene chloride, acetone and methanol respectively and the obtained product was dried overnight under vacuum at 40 ${ }^{\circ} \mathrm{C}$. In the same way, poly-N-acrylyl-8-aminoquinolione and poly-N-acrylylnaphtylamine were prepared.

\subsection{Synthesis of Poly-4-acryloxybenzalthiobarbituric Acid}

0.2 mole of polyacrylyl chloride was dissolved in THF and added drop-wise to a cold solution of 0.2 mole of 4-hydroxybenzalthiobarbituric acid and $20 \mathrm{ml}$ of triethylami ne in $100 \mathrm{ml}$ THF and stirred further for $24 \mathrm{~h}$ at room temperature. The reaction mixture was poured portion-wise into dilute solution of $\mathrm{HCl}$. The formed precipitate was washed thoroughly with subsequent amounts of dilute $\mathrm{HCl}$ solution, methanol, acetone and diethyl ether. The product was then finally dried overnight under vacuum at $40{ }^{\circ} \mathrm{C}$. 


\subsection{Effect of Modified Polyacrylic Acid on Thermal Stability of PVC}

A solution of $10 \mathrm{~g} \mathrm{PVC}$ was dissolved in $150 \mathrm{ml}$ THF was mixed with $0.2 \mathrm{~g}$ of modified polyacrylic acid dissolved in THF with stirring followed by sonication of the mixture to remove all the trapped gases during mixing. After that, the mixture was casted on a polypropylene sheet mounted on a horizontal glass plate. After evaporation of the solvents at room temperature, the obtained film was dried overnight under vacuum at room temperature. Modified polyacrylic acids used were polyacrylyloxybenzoic acid and polyacrylyloxybenzalthiobarbituric acid. The obtained film was then cut into strips and thermally treated at $100{ }^{\circ} \mathrm{C}$ for different intervals.

The discoloration extent of PVC blends attributed to dehydrohalogenation of $\mathrm{PVC}[16]$ was used as a function of thermal degradation of $\mathrm{PVC}$ and is related to the absorbance at $\lambda=400 \mathrm{~nm}$ for the blended films in comparison with a blank sample of PVC under comparable conditions. The absorbance was plotted against time of thermal treatment of PVC blends and calculated as an average of 3 replicates. Data of the investigation is summarized in Table 1.

Table 1. Effect of modified polyacrylic acid on the degradation of PVC

\begin{tabular}{c|c|c|c}
\hline Time, $\min$ & PVC & PVC+PBA & PTBA \\
\hline 0 & 0 & 0 & 0 \\
\hline 12 & 0.48 & 0.21 & 0.15 \\
\hline 24 & 1.22 & 1.09 & 0.19 \\
\hline 72 & 1.94 & 1.72 & 0.28 \\
\hline
\end{tabular}

\subsection{Metal Ion Recovery of Poly-2-acrylyloxybenzoic} Acid

$0.1 \mathrm{~g}$ portions of polyacrylyloxybenzoic acid were added separately to $100 \mathrm{ml}$ solution of the studied heavy metal ions in $100 \mathrm{mg} / \mathrm{l}$ concentration after adjusting its $\mathrm{pH}$ at $\sim 4.5$. These solutions were shaken for $1 \mathrm{~h}$. The polymer was filtered off and washed with double distilled water. The sorbed metal ions were eluted with $5 \mathrm{ml}$ of $2 \mathrm{M} \mathrm{HCl}$ and the metal ion uptake of the polymer (in $\mathrm{mg} / \mathrm{g}$ ) was calculated after determination of the eluted metal ions by ICP/AES technique.

\section{Results and Discussion}

\subsection{Characterization of Poly-2-acrylyloxybenzoic Acid}

Chemical modification of polyacrylic acid with benzoic acid was performed according to Scheme 1 .

FT-IR spectroscopic analysis in Figure 1 showed characteristic absorptions related to polyacrylic acid in addition to the absorption corresponding to the aromatic moiety at $1615 \mathrm{~cm}^{-1}$ and $1455 \mathrm{~cm}^{-1}$ beside the absorption of free carboxylic and ester $\mathrm{C}=\mathrm{O}$ groups at $1690 \mathrm{~cm}^{-1}$ and at $1740 \mathrm{~cm}^{-1}$, respectively and $\mathrm{OH}$ stretching at $3030 \mathrm{~cm}^{-1}$.

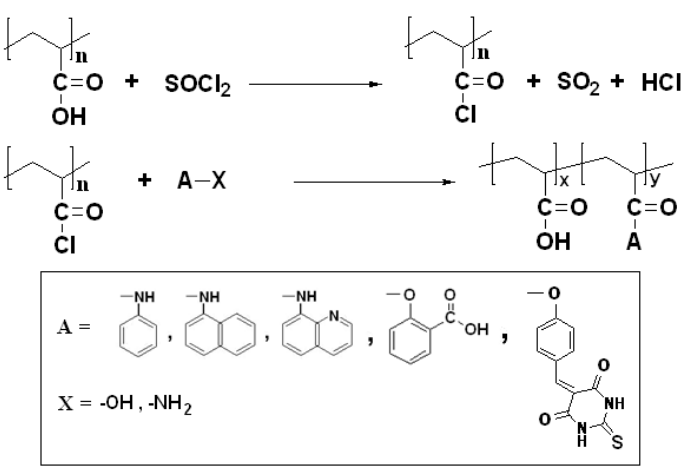

Scheme 1. Chemical modification of polyacrylic acid

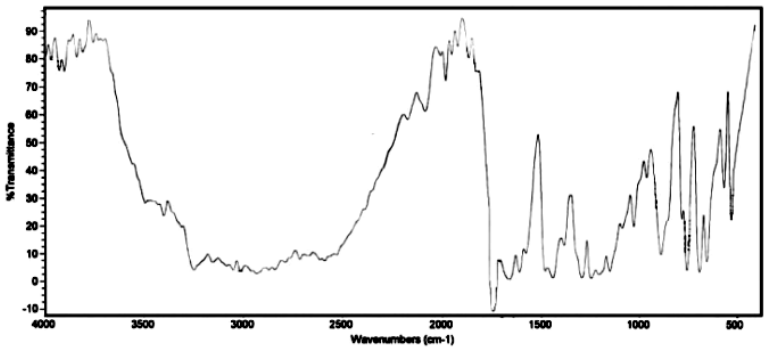

Figure 1. IR curve of poly-2-acryloxybenzoic acid

TGA of poly-2-acrylyloxybenzoic acid in Figure 2 showed that the weight loss started at about $95{ }^{\circ} \mathrm{C}$ and reached about $62 \%$ weight loss at $250{ }^{\circ} \mathrm{C}$. About further $14 \%$ at $410{ }^{\circ} \mathrm{C}$ was also observed which indicates that poly-2-acrylyloxybenzoic acid can be considered thermally stable up to $250{ }^{\circ} \mathrm{C}$. The weight loss in this case occurs mainly due to decarboxylation of polymer while the main chain C-C fission started at $420^{\circ} \mathrm{C}$.

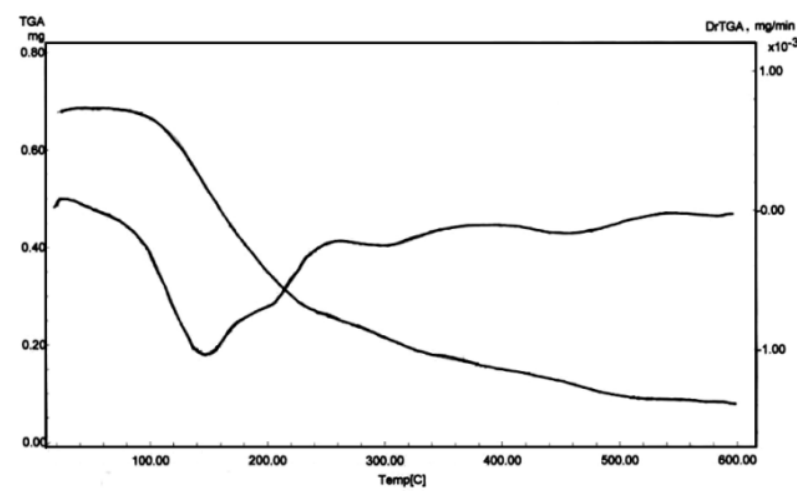

Figure 2. TGA of poly-2-acryloxybenzoic acid

\subsection{Characterization of Poly- $\mathrm{N}$-acrylylamines}

Chemical modification of polyacrylyl chloride with different amines such as aniline, $\alpha$-naphthylamine and 8-aminoquinoline was carried out according Scheme 1. FT-IR spectrum of poly-N-acrylylaniline in Figure 3a shows absorption band for $\mathrm{COCl}$ at $1660 \mathrm{~cm}^{-1}$ is absent, while the absorption bands of $\mathrm{N}-\mathrm{H}$ stretching and amidic $\mathrm{C}=\mathrm{O}$ groups appear at $3270 \mathrm{~cm}^{-1}$ and at $1610 \mathrm{~cm}^{-1}$, respectively indicating the successful modification of polyacrylyl chloride with aniline into polumer-supported amines. The same findings hold true for poly-N-acrylyl- $\alpha$-naphthylamine. There are 
also absorption bands at $1626 \mathrm{~cm}^{-1}$ related to $\mathrm{C}=\mathrm{C}$ (olefinic) and at $1570 \mathrm{~cm}^{-1}$ related to $\mathrm{C}=\mathrm{N}$ (aromatic) for poly-N-acrylyl-8-aminoquinoline shown in Figure $3 b$.

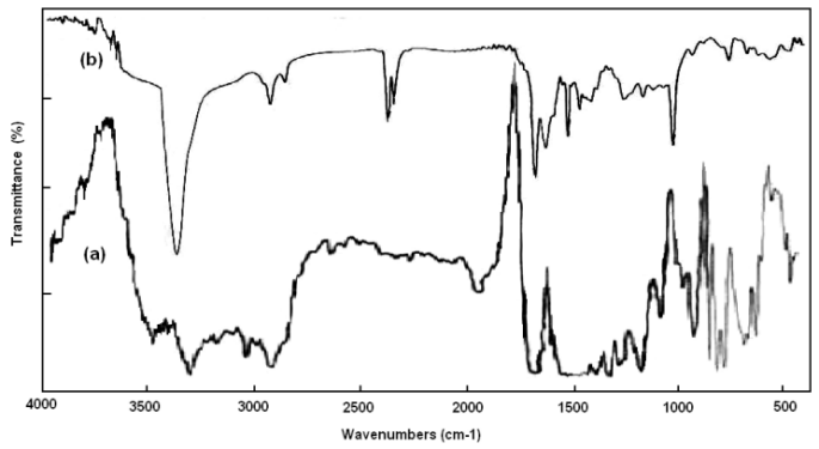

Figure 3. IR spectroscopic analysis of (a) poly-N-acrylylaniline and (b) poly-N-acryloyl-8-aminoqionoline

TGA of poly-N-acrylylaniline showed that the polymer is thermally stable up to $235{ }^{\circ} \mathrm{C}$ with weight loss of about $48 \%$ of the initial weight in addition to another weight loss of about $9.6 \%$ at about $530{ }^{\circ} \mathrm{C}$. This indicates that stability of the polymer against thermal effects is not very high and this may attributed to the ease of oxidation of the amino group followed by separation of aniline moiety from the polymer matrix. Figure 4 shows TGA of polyacrylic acid as a blank.

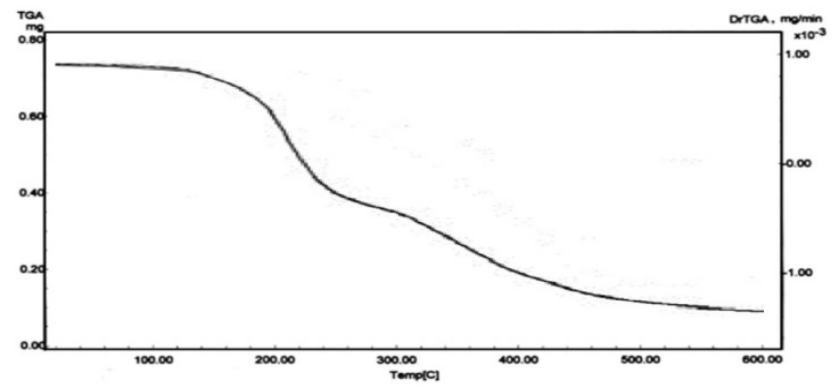

Figure 4. TGA polyacrylic acid

TGA for poly-N-acrylyl- $\alpha$-naphthylamine showed almost similar behaviour with weight loss of about $52 \%$ at $265{ }^{\circ} \mathrm{C}$. This reflects the relatively higher stability of polyacrylyl- $\alpha-$ naphthylamine against thermal effects than that for polyacrylylaniline. However, poly-N-acrylylaniline and poly-N-acrylyl- $\alpha$-naphthylamine showed higher thermal stability relative to that of polyacrylyloxybenzoic acid which suffers weight loss of about $62 \%$ until $250{ }^{\circ} \mathrm{C}$ that may be attributed to the ease of decarboxylation.

\subsection{Characterization of \\ Poly-4-acrylyloxybenzalthiobarbituric Acid}

Polyacrylyl chloride was reacted with4-hydroxybenzal-th iobarbituric acid to form polyacrylyloxybenzalthiobarbituric acid shown in Scheme 1. FT-IR spectroscopic analysis in Figure 5 showed absorption bands at $1170 \mathrm{~cm}-1$ related to $\mathrm{C}=\mathrm{S}$ bonds and at $1680 \mathrm{~cm}-1$ and $1726 \mathrm{~cm}-1$ related to $\mathrm{C}=\mathrm{O}$ (ketone) and $\mathrm{C}=\mathrm{O}$ (ester) groups, respectively.

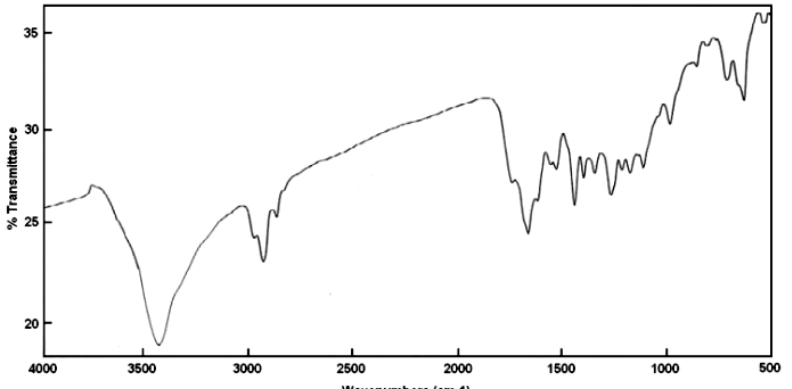

Figure 5. IR curve of poly-4-acryloxybenzalthiobabituric acids

TGA analysis of poly-4-acrylyloxybenzalthiobarbituric acid shown in Figure 6 indicates that this polymer starts to degrade at relatively high temperature of about $235^{\circ} \mathrm{C}$. Such weight loss attains about $52 \%$ of the original weight of the polymer sample.

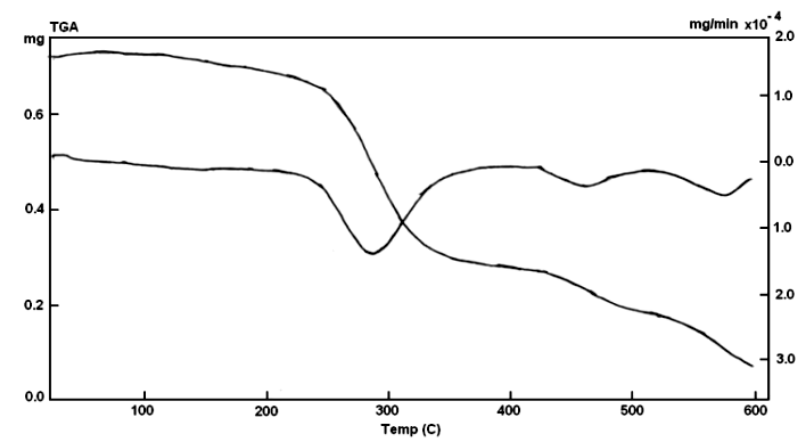

Figure 6. TGA of poly-4-acrylyloxybenzalthiobabituric acids

The first stage of the weight loss seems to be due to the rupture of $\mathrm{C}-\mathrm{O}$ bond leading to the liberation of thiobarbituric acid moiety. Raising the temperature leads to slight loss in weight attaining about $13.0 \%$ starting at $422{ }^{\circ} \mathrm{C}$ which may be attributed to $\mathrm{C}-\mathrm{C}$ bond fission. This can be concluding that the behavior of poly-4-acrylyloxybenzalthio barbituric acid is a typical behavior of normal polyolefins at higher temperatures.

\subsection{Stabilizing Effect of Modified Polyacrylic Acid on PVC}

Poly-4-acrylyloxybenzalthiobarbituric acid and polyacryl yloxybenzoic acid and were used as thermal stabilizers against autocatalytic dehydrochlorination reaction of PVC in presence of modified acrylic polymers. This reaction causes degradation of PVC which leads to a severe discoloration and lack of mechanical properties of PVC[16]. Thiobarbituric acid-supported polymer possesses a variety of functional groups able to interfere with the degradation process and also to absorb $\mathrm{HCl}$ produced by degradation of PVC. This results in reduction or delay of the harmful effect of acidic degradation products[17].

This can be proved by the stabilizing efficiency of modified polyacrylic acids on the treated PVC reflected by reducing the extent of discoloration of induced by thermal treatment of PVC in comparison with blank PVC. This can be attributed to the dehydrohalogenation of PVC under 
thermal treatment conditions[16,18,19]. Figure 7 shows a lower extent of discoloration of the treated PVC samples relative to blank sample. These results confirm a mechanism involving an interaction of the thiobarbituric acid moiety (OBT) from the polymer with the chlorine atoms emitted from the polymer and thus blocks the odd electron sites on PVC chains.

This action suppresses the possibility for conjugation rather than with $\mathrm{HCl}$ evolved. Presence of thiobarbituric acid with a spacer group of oxybenzal moiety helps for higher mobility of such side chains to catch emitted $\mathrm{HCl}$ relative to the directly attached thiobarbituric acid moiety to polymeric backbone.

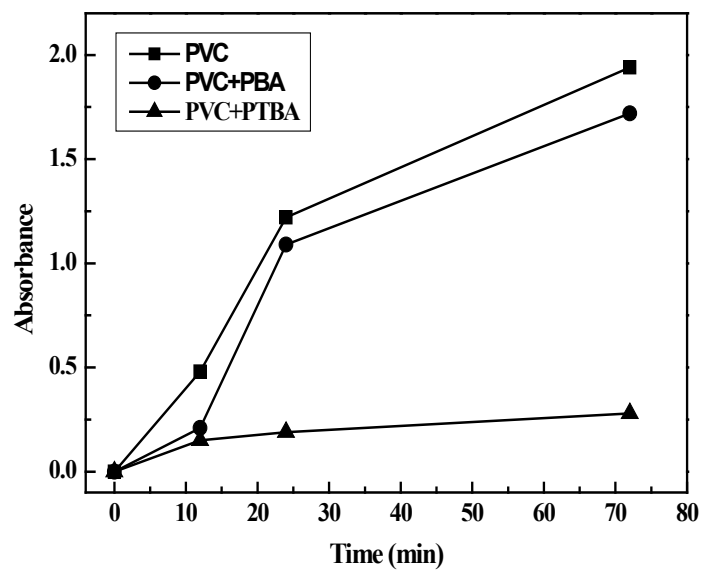

Figure 7. Time dependence of absorbance a function of discoloration extent of PVC heated at $100{ }^{\circ} \mathrm{C}$ in presence of modified polyacrylic acid as thermal stabilizer

\subsection{Application of Modified Polyacrylic Acid in of Metal Ion Recovery}

Modified polyacrylic acid with benzoic acid functionality was selected to be investigated for the recovery of metal ions from their aqueous solutions acting as ion exchanger or chelating agent. The sorption capacity of polyacrylyloxybenzoic acid in $\mathrm{mg} / \mathrm{g}$ for $\mathrm{Cd}(\mathrm{II}), \mathrm{Cu}(\mathrm{II}), \mathrm{Fe}(\mathrm{III})$ and $\mathrm{Co}$ (II) was $35.4,38.5,31,40 \mathrm{mg} / \mathrm{g}$ polymer, respectively, which is obviously higher than that for the polyacrylic acid without modification which showed a capacity of $20 \mathrm{mg} / \mathrm{g}$ polymer. The sorption process was adjusted at $\mathrm{pH}=4.5$ for all the investigated metal ions under stirring for $30 \mathrm{~min}$ and using $2 \mathrm{M} \mathrm{HCl}$ solution for elution of the metal ions out of the polymer matrix. From this investigation it is shown the different abilities of the modified polyacrylic acid to recover different metal ions from their aqueous solutions.

\section{Conclusions and Recommendations}

It can be concluded that the modified polyacrylic acid can be promising in many applications.

Poly-2-acrylyloxybenzoic acid showed thermal stability up to $250{ }^{\circ} \mathrm{C}$. Poly-N-acrylylaniline showed also thermal stability up to $235{ }^{\circ} \mathrm{C}$ while it was up to $265{ }^{\circ} \mathrm{C}$ for poly-N-acrylyl- $\alpha$-naphthylamine. Beside thermal stability up to $235{ }^{\circ} \mathrm{C}$, polyacrylyloxybenzalthiobarbituric acid showed also ability to be used as thermal stabilizer for PVC.

Polyacrylyloxybenzoic acid showed different abilities to recover different metal ions from their aqueous solutions which can be applied in many application directions such as metal ion recovery from their aqueous solutions.

\section{ACKNOWLEDGEMENTS}

This project was funded by the Deanship of Scientific Research (DSR), King Abdulaziz University, Jeddah, under grant no. 418/130/431. The authors, therefore, acknowledge with thank DSR technical and financial support.

\section{REFERENCES}

[1] Jones, C.F. and Grainger, D.W., "In vitro assessments of nanomaterial toxicity", Advanced Drug Delivery Reviews vol. 61, no. 6, pp. 438-458 (2009)

[2] Pan, B.-J.; Pan, B.-C.; Zhang, W.; Lv, L.; Zhang, Q. and Zheng, S., "Development of polymeric and polymer-based hybrid adsorbents for pollutants removal from waters", Chemical Engineering Journal, vol. 151, no. 1-3, pp. 19-29 (2009)

[3] Mahdavian, A.R. and Mirrahimi, M.A., "Efficient separation of heavy metal cations by anchoring polyacrylic acid on superparamagnetic magnetite nanoparticles through surface modification", Chemical Engineering Journal, vol. 159, no. 1-3, pp. 264-271 (2010)

[4] Wiśniewska, M., "Influences of polyacrylic acid adsorption and temperature on the alumina suspension stability", Powder Technology, vol. 198, no. 2, pp. 258-266 (2010)

[5] Guo, X.; Shao, H.; Hu, W.; Gao, W. and Chen, X., "Tannin and polyacrylic acid polarity and structure influence on the performance of polyvinylchloride ultrafiltration membrane", Desalination, vol. 250, no. 2, pp. 740-744 (2010)

[6] Ajji, Z. and Ali, A.M., "Separation of copper ions from iron ions using PVA-g-(acrylic acid/N-vinyl imidazole) membranes prepared by radiation-induced grafting", Journal of Hazardous Materials, vol. 173 no. 1-3, pp. 71-74 (2010)

[7] Ding, S.; Wei, W. and Yang, Z., "Composite colloids and patterning", Polymer, vol. 50, no. 7, pp. 1609-1615 (2009)

[8] Bhattarai, N.; Gunn, J. and Zhang, M., "Chitosan-based hydrogels for controlled, localized drug delivery", Advanced Drug Delivery Reviews, vol. 62, no. 1, pp. 83-99 (2010)

[9] Xie, D.; Yang, Y.; Zhao, J.; Park, J.-G. and Zhang, J.-T., "A novel comonomer-free light-cured glass-ionomer cement for reduced cytotoxicity and enhanced mechanical strength", Dental Materials, vol. 23, no. 8, pp. 994-1003 (2007)

[10] Moshaverinia, A.; Ansari, S.; Movasaghi, Z.; Billington, R.W.; Darrc, J.A. and Rehman, I.U., "Modification of 
conventional glass-ionomer cements with $\mathrm{N}$-vinylpyrrolidone containing polyacids, nano-hydroxy and fluoroapatite to improve mechanical properties", Dental Materials, vol. 24, no. 10, pp. 1381-1390 (2008)

[11] Mishra, S.; Rani, G.U. and Sen, G., "Microwave initiated synthesis and application of polyacrylic acid grafted carboxymethyl cellulose", Carbohydrate Polymers, vol. 87, no. 3, pp. 2255-2262 (2012)

[12] Kern, W. and Schulz, R.C., "Synthetic macromolecular substances with reactive groups", Angew. Chem., vol. 69, no. 5, pp. 153-171 (1957)

[13] Valuev I.L., Chupov V.V., Valuev L.I., "Chemical modification of polymers with physiologically active species using water-soluble carbodiimides", Biomaterials, vol. 19, no. 1-3, pp. 41-43 (1998)

[14] Kern, W., Hucke Th., Holländer R., Schneider R., "About hydrazide of polyacrylic. I. Preparation and Properties of Polyacrylic acid hydrazide", Makromol. Chem., vol. 22, no. 1, pp. 31-38 (1957)

[15] Abdel-Bary, E.M.; Abdelaal, M.Y.; Kenawy, I.M.; El-Sherbiny, I.; Moawad, E.B. \& El-Sayed, N.H.,
"Purification of waste water from heavy Metal ions using modified polymers", Mansoura Journal of Chemistry, vol. 36, no. 1, pp. 113-136 (2009).

[16] Hodgson, S.C.; Orbell, J.D.; Bigger, S.W. \& Scheirs, J., "Studying thermally induced chemical and physical transformations in common synthetic polymers: A laboratory project", J. Chem. Educ., vol. 77, no. 6, pp. 745-747 (2000)

[17] Sabaa, M.W.; Mohamed, N.A.; Khalil, Kh.D. \& Yassin, A.A., "Organic thermal stabilizers for rigid poly(vinyl chloride) II. Benzalthiobarbituric acid and some of its derivatives", Polymer Degradation and Stability, vol. 70, no. 2, pp. 121-133 (2000).

[18] Iidaa, T. \& Gotoa, K., "Color Stabilization of Polyvinyl Chloride) with Heat Treatment", J. Macromol. Sci.: Part A Chemistry, vol. 12, no. 3, 389-399 (1978).

[19] Czakóa, E.; Vymazala, Z.; Vymazalováa, Z.; Skalský1, J. \& Štěpeka, J., " Effect of stabilizers in the thermal treatment of PVC-V. Effect of $\mathrm{Ba}$ and $\mathrm{Cd}$ butyrates, 2-ethylhexoates, laurates and stearates on the dehydrochlorination of PVC", European Polymer Journal, vol. 14, no. 12, pp. 1011-1014 (1978) 